method which accrued from their ideas. This method allows each scientist to be studied in depth, and each biography is sufficiently long for the purpose. The contributing authors are R. Harré on Gilbert and Kepler, J. J. Macintosh on Bacon, M. Deutcher on Descartes, D. Knight on Galileo, D. Goodman on Harvey and J. Mepham on Van Helmont.

The paper-back of only 188 pages must be considered expensive when compared with other books of similar size.

W. L. SUMNER

\section{Science in History}

By J. D. Bernal. Third edition. Pp. xxvii +1039 . (London: C. A. Watts and Co., Ltd., 1965.) $84 s$.

GOR this third edition, Prof. Bernal has almost completely re-written Part 6 of the earlier editions of Science in History, with the exception of the chapter on the social sciences in history. Part 7, which contains his conclusions and is entitled Science and History, is sub. stantially unchanged, apart from some factual corrections bringing it more up to date and the addition of a section "Science in a Rapidly Changing World", as well as some new paragraphs dealing with, for example, the organiza tion of scientists, information services, and secrecy: a few paragraphs have been omitted, and others, like that on science in the developing countries, revised. Apart, therefore, from the bulk of Part 6, constituting some 328 pages out of a total of 978 and containing in successive chapters brilliant reviews of the physical sciences and of the biological sciences in the twentieth century, the book is substantially unchanged, and reflects the weaknesses that have attracted criticism in the earlier editions. Prof. Bernal is too enthusiastic an exponent of Marxism for his book to be fairly described as history in any true sense: his enthusiasm leads him to make the most naïve and questionable assertions as if they were generally accepted propositions. If his failure to discriminate between opinion and fact makes part of the book still misleading for the immature and less informed, the brilliance of those two chapters on the physical and biological sciences alone makes the book worth reading. The bibliography includes many references to publications since the first edition appeared in 1954. R. BRTGHTMAN

\section{Mathematical Discovery}

On Understanding, Learning, and Teaching Problem Solving. Vol. 2. By G. Polya. Pp. xi+191. (New York, London and Sydney: John Wiley and Sons, Inc., 1965.) $42 s$.

IO competent teacher of mathematics can afford to be 1 ignorant of the sequence of books by Polya on the art and science of solving mathematical problems, in which the author shows how the seemingly subconscious processes of discovery and proof, as described by Poincaré and analysed by Hadamard, can be assisted and developed by conscious organization. His examples are taken from the elementary ranges of school mathematics, but they serve to illustrate how to discard blind alleys and find through routes, how to search for equivalent and possibly simpler results, how to strip away inessentials by looking at generalizations, how to acquire by experience the skill in selecting the right tool for the job. How would you set about finding the volume of the frustum of a pyramid ? In the theorem that if three circles having the same radius pass through a point, the circle through the other three points of intersection has the same radius, how can we organize our knowledge in such a way as to lead us to the hinge on which the result turns? The whole book is packed with case-histories in the anatomy and psychology of mathematical discovery, chosen from simple algebra, geometry and trigonometry by one who has proved himself a master of recondite research. It should be in every school library, to be read by every teacher of mathematics and by every pupil who aspires to a genuine knowledge and understanding of mathematies; and it will make all readers envious of those who have had the privilege of attending Polya's seminars in problem solving, given for high-school teachers at Stanford University.

T. A. A. Broadbent

\section{The Physics of Ice}

By Prof. E. R. Pounder. (The Commonwealth and International Library: Geophysies Division.) Pp. vii 151. (London and New York: Pergamon Press, 1965.) $17 s$. $6 d$. net.

CE is a substance the properties and peculiarities of which are of interest in many fields of science and technology. Its more unusual properties can be attributed to a lack of symmetry and resulting dipole moment of the water molecule itself, which is preserved in the ice lattice. Prof. Pounder has found that the physics of ice in its broadest context is too extensive a subject to be discussed within the confines of a paperback, and, in The Physics of Ice, has limited himself to topics related to his own speciality, sea ice. Indeed, the "Physics of Sea Ice" would have been a much more realistic title, as fundamentals are examined only so far as is necessary for an understanding of this subject. The author is professor of physics in McGill University, which has had a research tradition in ice physics since the classic work of Barnes on ice structure forty years ago.

The first four chapters give an account of the formation. break up and climatology of sea and lake ice which will make interesting reading for sixth form students upwards. The structure of the ice depends on the meteorological conditions during its formation, and analysis of thin sections in polarized light enables some deductions to be made about its history. The remainder of the book, concerned with crystallographic properties of ice, its rheology, and the influence of brine inclusions on thermal and electrical properties, is discussed at a somewhat higher. level-to be easily followed by the second year undergraduate. It is a pity that the author did not lay greater emphasis in this section on the role of lattice defects in ice, in view of their fundamental influence on mechanical and electrical properties. The literature of this subject is necessarily rather scattered, and the book concludes with a list of useful references. Many of these are, how ever, in reports which are unfortunately difficult to obtain.

This is a book to be read by the physies student as at source of interesting problems for discussion, and to serve as a useful reference for those more directly concerned with polar research.

J. Hallet T

\section{The Special Theory of Relativity}

By Prof. David Bohm. (Lecture Notes and Supplements in Physics.) Pp. xiv + 236. (New York and Amsterdam: W. A. Benjamin, Inc., 1965.) 7.70 dollars.

THE Special Theory of Relativity is neither a populau. treatment of special relativity nor a conventional text-book but lies somewhere between the two. The author does not try to avoid mathematics in the way that a popular writer does, but on the other hand he only uses mathematics when it is essential, and relies on physical ideas whenever possible. This makes it a most satisfactory book for background reading for anyone learning special relativity. Moreover, the author brings to his subject the benefit of long experience, both in using the theory and in teaching it, so that nearly every detail in the subject has a new and unexpected light thrown on it. His approach is by way of electrodynamics and the Lorentz electron theory. He uses the difficulty of determining when events are simultaneous in this theory to motivate the Lorentz transformation, and then he considers at length the way in which our common sense concepts of space and time have to be modified. Various applications of relativity, 